\title{
Plano amostral para coleta de serapilheira na Floresta Ombrófila Mista do Rio Grande do Sul
}

\author{
Sufficency sample for litter collection in araucaria forest, $R S$
}

Fabiano de Oliveira Fortes ${ }^{\mathrm{I}}$ Alessandro Dal’Col Lúcio ${ }^{\mathrm{II}}$ Lindolfo Storck $^{\mathrm{II}}$

\section{RESUMO}

O trabalho foi realizado na Floresta Ombrófila Mista, de grande diversidade tipológica, em São Francisco de Paula, Rio Grande do Sul. O objetivo foi estimar a serapilheira acumulada, coletada com diferentes tamanhos de molduras $e$ determinar a intensidade amostral em cada estação sazonal. Foram obtidas 15 amostras aleatórias por hectare para cada moldura em cada estação sazonal. A serapilheira foi separada nos estratos folhas, cascas, galhos e miscelâneas, foi secada e

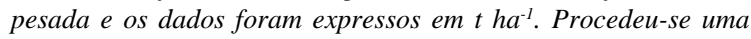
análise de variância conjunta com as fontes de variação "moldura, estação, interação e erro". Foi estimada a média, a variância e o coeficiente de variação e foi realizado o teste de homogeneidade das variâncias entre as estações e entre as molduras. Admitindo-se um erro de amostragem máximo de 10, 15, 20 e 25\% da média estimada, calculou-se a intensidade de amostragem, por hectare, para população infinita. A interação entre moldura e estação não foi significativa para a serapilheira e para os estratos e nem houve diferenças significativas entre as molduras. As variâncias da serapilheira foram homogêneas entre as molduras nas quatro estações e foram heterogêneas entre as estações nas quatro molduras. É preferido usar a moldura muito pequena $\left(0,25 \mathrm{~m}^{2}\right)$, com 27 unidades de amostra no inverno, 25 na primavera, 33 no outono e 15 no verão para uma precisão de $15 \%$ de diferença entre as médias.

Palavras-chaves: tamanho de moldura, intensidade amostral, homogeneidade das variâncias.

\section{ABSTRACT}

The present research was accomplished in the Forest Mixed Ombrófila of São Francisco de Paula - FLONA, being this representative of great diversity in the State of Rio Grande do Sul. The objective was to esteem the accumulated burlap collected with four different collecting frames and the amostral intensity in each seasonal station. 15 random samples were collected for each frame by hectare in each seasonal station being separated in the stratus leaves, peels, branches and miscellany. It was used a completely random design in each station, for subsequent accomplishment for the united analysis of the experiments. The means, the variance, and the variation coefficient was calculated for all the strata, being accomplished the test of homogeneity of the variances. Through the simple aleatory sampling, being admitted a maximum sampling mistake of 10, 15, 20 and 25\% of the esteem means, with 5\% of error probability, the sampling intensity was calculated by hectare, for infinite population. The interaction between frame and station, in the joint analysis, was not significant for the total and the stratus, soon the behavior of the frames was the same in the different stations. The variances, verified among inside the frames of the stations, were homogeneous in relation with the accumulation of burlap. The effect of the frames for the total and for the stratus, branches, peels and miscellany they didn't differ to each other, only presenting significant difference in the leaves. There were not significant differences among the frames for the total, the most appropriate was like this the very small frame $\left(0,25 \mathrm{~m}^{2}\right)$, and in the winter with 27 samples, in the spring, 25, in the autumn, 33 and in the summer, 15 units, are necessary to obtain 15\% of difference between the means.

Key words: size of plot, sufficiency samples, homogeneity of variances.

\section{INTRODUÇÃO}

Das formações florestais do Rio Grande do Sul, a Floresta Ombrófila Mista é a que possui a maior

IPrograma de Pós-graduação em Engenharia Florestal, Centro de Ciências Rurais (CCR), Universidade Federal de Santa Maria (UFSM), Santa Maria, RS, Brasil. E-mail: fabianofortes@mail.com.br.

ID Departamento de Fitotecnia, CCR, UFSM, 97105-900, Santa Maria, RS, Brasil. E-mail: adlucio@smail.ufsm.br.*Autor para correspondência. 
diversidade quanto às espécies e é a segunda em cobertura florestal do Estado, com área de $9.195,65 \mathrm{~km}^{2}$, cobrindo 3,25\% da área total e 18,64\% de cobertura florestal do Rio Grande do Sul (RS). Segundo o Inventário Florestal Contínuo do Rio Grande do Sul(SEMA-RS/UFSM, 2001), por ser uma floresta de transição, tem características próprias, assim como formações da Floresta Decidual e Semidecidual. Assim, por causa da importância da Floresta Ombrófila Mista na formação fitogeográfica do Estado e da grande variabilidade existente neste ecossistema, a Floresta Nacional de São Francisco de Paula torna-se uma área representativa dessa formação para o estudo de tamanho e intensidade amostral de coletores de serapilheira.

Considera-se serapilheira acumulada todo o material depositado na superfície do solo de uma floresta em uma determinada época. Já a produzida, também chamada de depositada, refere-se ao material que cai dentro de coletores de tamanhos pré-fixados por unidade de tempo ou por um dado número de dias. Tanto a serapilheira acumulada quanto a depositada são divididas em estratos como folhas, ramos, cascas, raízes, galhos, frutos e miscelânea (POGGIANI \& SCHUMACHER, 2000). Em diferentes ecossistemas florestais podem ser depositadas diferentes quantidades de serapilheira e esta, por sua vez, pode apresentar diferentes proporções de estratos pelo fato de a floresta nativa ser mais heterogênea, mudando de acordo com a tipologia e a composição de espécies.

O conhecimento de serapilheira depositada, a velocidade com que se decompõe e o retorno de nutrientes que estes promovem ao solo são informações importantes para o balanço de nutrientes dentro do ecossistema florestal e podem auxiliar na determinação do grau de fragilidade desses ecossistemas (GALLON, 2004). Entre os fatores que afetam a quantidade de resíduos produzidos, CORREIA \& ANDRADE (1999) comentam que os mais relevantes são os elementos climáticos (precipitação e temperatura). Porém, SANTOS \& VÁLIO (2002), estudando o acúmulo de serapilheira numa floresta tropical durante o período de novembro de 1996 a setembro de 1998 e suas possíveis relações entre fatores climáticos (precipitação pluviométrica, fotoperíodo e temperatura), constataram uma correlação fraca entre o acúmulo de serapilheira e os fatores climáticos. Entretanto, regiões com alto índice pluviométrico, em geral, produzem maior quantidade de serapilheira em comparação com as regiões de baixo índice pluviométrico (GONZALEZ \& GALLARDO, 1982).

Na Floresta Estacional Decidual em Santa Maria, RS, foram encontradas as menores deposições de serapilheira no outono e as maiores na primavera, chegando a 7,76t ha-1 ano-1 (CUNHA et al., 1993), com $66 \%$ do estrato folhas. CUNHA (1997), estudando a mesma tipologia na região central do Rio Grande do Sul, encontrou 9,5t ha- ano $^{-1}$ para floresta secundária com mais de 30 anos e KÖNIG et al. (2002) encontraram $67,8 \%$ de folhas, 12,9\% miscelâneas e 19,3\% de galhos, porém, os autores comentam que foram considerados galhos menores que um centímetro de diâmetro. Na Floresta Ombrófila Mista em São Francisco de Paula, RS, BACKES et al. (2000) encontraram 7,2t ha-1 ano ${ }^{-1}$ até $7,9 \mathrm{t} \mathrm{ha}^{-1} \mathrm{ano}^{-1}$ de deposição de serapilheira e acúmulo de $16,7 \mathrm{t}$ ha ${ }^{-1}$ com uma variação de $9,4 \mathrm{tha}^{-1}$ a $3,8 \mathrm{t} \mathrm{ha}{ }^{-1}$. Passados cinco anos na mesma tipologia, BACKES et al. (2005) encontraram 10,3t ha ${ }^{-1}$ ano $^{-1}$ de deposição e $14,2 \mathrm{t} \mathrm{ha}^{-1}$ de serapilheira acumulada. FERNANDES \& BACKES (1998) afirmam que os processos de decomposição são influenciados pelas variações sazonais, sobretudo da temperatura, e que a queda de serapilheira é praticamente contínua durante todo o ano e, em conseqüência, aumenta a quantidade de resíduos vegetais acumulados sobre o solo da floresta.

A estimativa da serapilheira também pode ser influenciada pelo tamanho e pela forma das molduras utilizadas nas coletas, fazendo com que o acréscimo ou o decréscimo no tamanho da moldura influencie diretamente o número de repetições necessárias para se ter confiabilidade da média estimada. A realização de trabalhos que visem a complementar e melhor elucidar a confiabilidade dos parâmetros amostrais estudados para análise de nutrientes vem ao encontro dos conceitos de sustentabilidade para que se torne viável um sistema de manejo de florestas nativas no sul do país com características próprias.

Em levantamentos, existe a necessidade de avaliar o tamanho da amostra, se esta é suficientemente grande para uma dada precisão requerida pelo pesquisador, e se, na estimativa indicada pelo número necessário de unidades de amostra, estará o universo populacional (PILLAR, 2004). Também é necessário decidir quanto ao método de seleção e, em alguns casos, o tamanho e a forma das unidades amostrais que irão compor a amostra, especialmente em ecologia, em que o meio amostrado nem sempre se enquadra nas condições ideais tratadas pela estatística.

Em experimentos de campo, o aumento do tamanho da parcela reduz o coeficiente de variação (PIMENTEL GOMES, 1984), levando muitos experimentadores a preferirem parcelas grandes para trabalhar com um CV menor, sem perceber que estes tipos de parcelas acarretam menor número de repetições e, assim, reduzem a precisão do experimento. Porém, com a redução do tamanho das parcelas e o aumento 
do número de repetições, ocorre o aumento do custo de coleta em conseqüência, sobretudo do deslocamento.

De acordo com a área estudada, o aumento da sua variância acarretará um maior número de parcelas necessárias para se ter idéia da variabilidade existente no meio. Para diminuir a variância da média, o aumento do número de repetições é a melhor opção, desde que o experimento seja bem planejado. Assim, o número de repetições é um fator que é afetado diretamente pelo tamanho e pela forma das parcelas e, para garantir uma satisfatória precisão da estimativa do erro, de acordo com MIRANDA (1978), esse número de repetições deve ser suficientemente grande para incluir toda a variabilidade existente.

Pesquisas que quantificam o material acumulado e depositado são baseadas em mão-de-obra e experiências dos pesquisadores, sendo que o número de coletores necessários por hectare é estipulado de acordo com o pesquisador e não por região fitogeográfica ou ecossistemas. De forma geral, não há uma padronização na definição do tamanho da moldura utilizada na coleta da serapilheira nem na intensidade amostral, sendo que as mais utilizadas variam de $0,25 \mathrm{~m}^{2}$ (CUNHA et al., 1993; BORÉM \& RAMOS, 2002; MOREIRA \& SILVA, 2004) a $1,00 \mathrm{~m}^{2}$ (SOUZA \& DAVIDE, 2001; SANTOS \& VÁLIO, 2002; SCHUMACHER et al., 2004), com intensidade amostral de quatro (VITAL et al., 2004) a 30 parcelas amostradas (KÖNIG et al., 2002). Essa variação pode induzir um pesquisador a definir de forma empírica, sem maiores confirmações estatísticas, o melhor tamanho da moldura e a intensidade amostral, podendo assim sub ou superestimar os valores das variáveis observadas no experimento, inflacionando, conseqüentemente, a variância residual.

Assim, o presente trabalho tem por objetivo determinar o tamanho da moldura e a intensidade amostral para coleta de serapilheira acumulada em Floresta Ombrófila Mista, e suas variações nas estações sazonais.

\section{MATERIAL E MÉTODOS}

O estudo foi realizado na Floresta Nacional, localizada no Rincão dos Kroeff, município de São Francisco de Paula, na região Nordeste do Estado do Rio Grande do Sul. A floresta, sob a responsabilidade do Instituto Brasileiro do Meio Ambiente, está entre as coordenadas $29^{\circ} 23^{\prime}$ e $29^{\circ} 27^{\prime}$ de latitude Sul e $50^{\circ} 23^{\prime}$ e $50^{\circ} 25^{\prime}$ de longitude Oeste. O local é conhecido como microrregião dos Campos de Cima da Serra, zona de transição entre a Floresta Ombrófila Densa e a Floresta
Ombrófila Mista. O clima da área de estudo, de acordo com a classificação de Köppen, é do tipo “Cfb”, mesotérmico médio (MORENO, 1961). O relevo é ondulado com altitudes de 930m na parte norte, já na parte sul é acidentado, formando cânions com mais de 100m de profundidade, característico da área onde foi realizado o estudo (IBAMA, 2000). Os solos estão classificados em Cambisol Húmico Álico, de textura argilosa, substrato basáltico, de teor ácido com teores de Alumínio trocável, Chernossolo Argilúvico Férrico e Neossolo Litólico Eutrófico (STRECK et al., 2002).

O levantamento dos dados foi realizado em quatro áreas de um hectare cada, com características semelhantes e não muito distantes entre si. Nestas áreas não ocorreu manejo ou intervenção silvicultural nos últimos 30 anos. A altitude das áreas amostradas está em torno dos 1000m do nível do mar. Cada uma das áreas foi avaliada em estação sazonal diferente (primavera, verão, outono e inverno). Em cada estação sazonal foram marcados aleatoriamente15 pontos de coletas da serapilheira para cada um dos quatro tamanhos de molduras coletoras: a) Grande $(\mathrm{G})=1 \mathrm{~m} \mathrm{x}$ $1 \mathrm{~m}\left(1 \mathrm{~m}^{2}\right)$; b) Média $(\mathrm{M})=1 \mathrm{~m} \times 0,75 \mathrm{~m}\left(0,75 \mathrm{~m}^{2}\right)$; c) Pequena $(\mathrm{P})=0,75 \mathrm{~m} \times 0,75 \mathrm{~m}\left(0,56 \mathrm{~m}^{2}\right)$ e d) Muito Pequena $(\mathrm{MP})=$ $0,5 \mathrm{~m} \times 0,5 \mathrm{~m}\left(0,25 \mathrm{~m}^{2}\right)$.

Considerou-se serapilheira toda matéria orgânica morta acima do solo. Nos casos onde a serapilheira ficou parte dentro e parte fora da moldura, foi coletada apenas a parte que estava no interior das mesmas. O material coletado foi acondicionado em sacos plásticos e etiquetado e, posteriormente, foi levado ao Laboratório do Departamento de Fitotecnia da Universidade Federal de Santa Maria, sendo separado por estratos (folhas, cascas, galhos e miscelâneas) e colocado em sacos de papel. Para a secagem, usou-se uma estufa com temperatura de $75^{\circ} \mathrm{C}$ até peso constante. A pesagem foi realizada com balança de precisão de $0,1 \mathrm{~g}$. Os valores de cada estrato foram transformados para toneladas por hectare, para permitir a comparação entre os diferentes tamanhos de molduras.

Os dados obtidos para o peso seco da serapilheira e respectivos estratos (folhas, cascas, galhos e miscelâneas) foram analisados, em cada estação sazonal, considerando o delineamento inteiramente casualizado, com quatro tamanhos de molduras como tratamento e os pontos de coleta dentro de cada estação sazonal como 15 repetições. Em seguida, foi realizada uma análise da variância conjunta, considerando as seguintes fontes de variação: quatro tamanhos de molduras (G, M, P e $\mathrm{MP}$ ), quatro estações sazonais (primavera, verão, outono e inverno), interação entre tamanho de 
moldura e estações e erro, para verificar o comportamento das molduras nas diferentes estações. O efeito da estação sazonal foi considerado aleatório, gerando assim interação também aleatória (STEEL et al., 1997).

Para cada combinação de tamanho de moldura e estação sazonal e para os níveis de tamanho de moldura e estação, foram estimadas a média, a variância e o coeficiente de variação. A homogeneidade das variâncias entre tamanhos de molduras dentro de cada estação e entre estação dentro de cada tamanho de moldura foi testada pelo teste de Bartlett (STEEL et al., 1997). Para os cálculos, foi utilizado o aplicativo Excel.

Considerando os resultados da análise da variância (diferenças entre tamanhos de molduras, variabilidade entre estações e interação) e dos testes de homogeneidade das variâncias, foi estimada a intensidade amostral necessária, com 5\% de probabilidade de erro, para a área de um hectare. Assim, o valor de $n$ foi estimado pela expressão $n \cong t^{2} s_{x}^{2} / E^{2}$, em que t é o valor da tabela t de Student $(a=5 \%$ de probabilidade de erro bilateral); $s^{2}{ }_{x}$ é a estimativa da variância; $E=L E *$ m/100; LE é o limite de erro de estimação, estipulado como sendo igual a 10, 15, 20 e 25\%; mé a média aritmética (STEEL et al., 1997).

\section{RESULTADOS E DISCUSSÃO}

Para a serapilheira coletada, bem como para os diferentes estratos da serapilheira (galho, casca, folha e outros), a interação entre as molduras coletoras com as diferentes estações sazonais não foi significativa. Também não existem diferenças significativas entre os tamanhos de molduras (MP, P, M e G), com exceção do estrato folha. Assim, com exceção do estrato folha, os valores coletados com qualquer um dos diferentes tamanhos de molduras valem para qualquer uma das quatro estações sazonais (primavera, verão, outono e inverno).

Não seria prático usar um tamanho diferente de moldura apenas para o estrato folha e, por isso, pode ser adotado um tamanho único de moldura para a serapilheira e todos os seus estratos. Nesta condição, não havendo diferença entre os tamanhos de molduras (Tabela 1) e por questões práticas de redução do volume de trabalho na coleta e na separação do material, pode ser adotada como moldura adequada a muito pequena (MP), ou seja, de $0,25 \mathrm{~m}^{2}$, em todas as estações sazonais, tendo em vista que a interação não foi significativa.

Na tabela 1, pode ser observada a variação dos valores da serapilheira coletados entre as estações sazonais dentro de cada tamanho de moldura e na média geral das estações. Os maiores valores de serapilheira foram observados no inverno com 10,91t ha-1 para a moldura MP e 9,30t ha-1 para a moldura G. Por outro lado, os menores valores foram observados no outono, com variação de 4,89 a 3,38t ha-1 . Verificou-se também uma forte variação sazonal, chegando a uma diferença de 5,78t ha-1 ao comparar a média do inverno com a média do outono. Na primavera e no verão, os valores médios foram intermediários, entre 6,30 e 5,65t ha-1, respectivamente.

Tabela 1 - Média $(\bar{m})$, variância $\left(\mathrm{s}^{2}\right)$ e coeficiente de variação (CV) para a serapilheira coletada $\left(\mathrm{t} \mathrm{ha}^{-1}\right)$ em diferentes estações sazonais (inverno, primavera, verão e outono) e molduras coletoras do tipo muito pequena (MP), pequena (P), média (M) e grande (G) na Floresta Ombrófila Mista de São Francisco de Paula, RS. Santa Maria - RS, 2007.

\begin{tabular}{lllllll}
\hline Molduras & & Invemo & Primavera & Verão & Outono & Média \\
\hline \multirow{3}{*}{ MP } & $\bar{m}$ & 10,91 & 7,28 & 5,92 & 4,50 & 7,15 \\
& $\mathrm{~s}^{2}$ & 17,05 & 6,80 & 2,57 & 3,56 & 7,50 \\
& $\mathrm{CV}(\%)$ & 37,86 & 35,82 & 27,05 & 41,82 & 35,64 \\
$\mathrm{P}$ & $\bar{m}$ & 9,43 & 5,80 & 5,14 & 3,38 & 5,94 \\
& $\mathrm{~s}^{2}$ & 19,34 & 2,52 & 1,71 & 2,50 & 6,52 \\
& $\mathrm{CV}(\%)$ & 46,65 & 27,34 & 25,49 & 46,77 & 36,56 \\
$\mathrm{M}$ & $\bar{m}$ & 10,47 & 5,20 & 5,97 & 4,22 & 6,47 \\
& $\mathrm{~s}^{2}$ & 13,40 & 2,46 & 1,47 & 3,57 & 5,23 \\
$\mathrm{G}$ & $\mathrm{CV}(\%)$ & 34,95 & 30,20 & 20,31 & 44,83 & 32,57 \\
& $\bar{m}$ & 9,30 & 6,92 & 5,56 & 4,89 & 6,67 \\
& $\mathrm{~s}^{2}$ & 11,51 & 6,90 & 1,92 & 3,29 & 5,91 \\
Média & $\mathrm{CV}(\%)$ & 36,45 & 37,97 & 24,90 & 37,08 & 34,10 \\
& $\bar{m}$ & 10,03 & 6,30 & 5,65 & 4,25 & 6,56 \\
& $\mathrm{~s}^{2}$ & 15,33 & 4,67 & 1,92 & 3,23 & 6,29 \\
\hline
\end{tabular}


No inverno, com as baixas temperaturas e uma menor radiação solar, ocorre uma redução e ou uma estagnação dos microorganismos que decompõe a matéria orgânica do solo, conseqüentemente, ocorre uma menor ciclagem do material depositado na floresta. Assim, nessa estação a deposição de serapilheira acumulada no solo torna-se maior que a decomposição, ocasionando uma maior quantidade de material encontrado. Autores como BORÉM \& RAMOS (2002), ARATO et al. (2003) e VITAL et al. (2004) encontraram, no final da estação seca, os maiores valores de serapilheira depositada, sendo que esta ocorre até o final do mês de setembro, incluindo inverno e parte da primavera. Salienta-se que, no local de realização do trabalho dos autores citados, existem duas estações definidas (seca e chuvosa), enquanto que, no Rio Grande do Sul, existem quatro estações bem definidas (outono, inverno, primavera e verão). Além disso, KÖNIG et al. (2002) encontraram as maiores produções de serapilheira no período de inverno na Floresta Estacional Decidual, corroborando os resultados obtidos.

No verão, a menor relação do gradiente deposição/decomposição, com a elevação da radiação solar, da temperatura do ar e do solo, favorece o aumento da atividade microbiana no solo que, por sua vez, diminuiu a quantidade absoluta de material depositado em razão da menor quantidade de serapilheira depositada na estação anterior (primavera), quando comparada com o inverno, aumentando o ciclo de saída e diminuindo o de entrada. Assim, foi verificada no outono (Tabela 1) uma menor quantidade de serapilheira depositada, mesmo que, nesta estação ocorra um aumento na deposição de folhas, porém, o estrato que mais influencia a deposição da serapilheira nesta tipologia é o de galhos.
Nas estações sazonais verão e outono, são observadas as menores médias de serapilheira, o que confere com as observações de CUNHA et al. (1993) na Floresta Estacional Decidual. Autores que realizaram trabalhos onde existem duas estações definidas, como BORÉM \& RAMOS (2002), ARATO et al. (2003) e VITAL et al.(2004), encontraram os menores valores de serapilheira no período chuvoso, correspondendo às estações verão e outono, comportamento este também observado neste estudo (Tabela 1).

Observando as variâncias da serapilheira (Tabela 1), é no inverno que houve maior heterogeneidade. No entanto, em todas as estações sazonais, a variância entre os tamanhos de molduras foram homogêneas (Tabela 2). Por outro lado, como também houve variação dos valores de serapilheira entre as estações, as variâncias foram heterogêneas em nível de 5\% de probabilidade de erro, para todos os tamanho de molduras. Apesar disso, não foram evidenciadas as maiores estimativas de CV no inverno, por apresentarem altos valores da média, tornando os CVs baixos, dentro de suas respectivas molduras e na média. Assim, a variabilidade existente é devido às estações, principalmente ao inverno, e não devido aos diferentes tamanhos de moldura, uma vez que, ao variar as molduras dentro das estações, foi verificada a homogeneidade (Tabela 2). Dessa forma, deve ser considerada uma intensidade de amostragem diferente para cada estação sazonal, podendo ser definido um único tipo de tamanho de moldura coletora, no caso a MP.

Ao se estimar a intensidade amostral para o tamanho de moldura coletora muito pequena, definido como a mais adequada, dentro de cada estação sazonal (Tabela 3), pode-se comprovar que houve diferenças entre as estações, mantendo-se constante o tipo de

Tabela 2 - Comportamento da variância, para diferentes estratos (galhos, cascas, folhas, miscelâneas e total) entre molduras por estações sazonais e entre estação por molduras coletoras do tipo muito pequena (MP), pequena (P), média (M) e grande (G), no estudo de serapilheira acumulada na Floresta Ombrófila Mista de São Francisco de Paula, RS. Santa Maria - RS, 2007.

\begin{tabular}{|c|c|c|c|c|c|}
\hline \multirow{2}{*}{ Estações sazonais } & \multirow[b]{2}{*}{ Galhos } & \multirow[b]{2}{*}{ Cascas } & \multirow[b]{2}{*}{ Folhas } & \multirow[b]{2}{*}{ Miscelâneas } & \multirow[b]{2}{*}{ Tota } \\
\hline & & & & & \\
\hline Inverno & hom. & het. & hom. & hom. & hom. \\
\hline Primavera & het. & het. & hom. & hom. & hom. \\
\hline Verão & hom. & hom. & hom. & hom. & hom. \\
\hline Outono & hom. & hom. & hom. & het. & hom. \\
\hline \multirow{2}{*}{ Tamanho da moldura } & & riância de & Iras em c & tações sazonai & ------ \\
\hline & Galhos & Cascas & Folhas & Miscelâneas & Total \\
\hline MP & hom. & het. & het. & het. & het. \\
\hline $\mathrm{P}$ & het. & het. & het. & het. & het. \\
\hline M & het. & het. & het. & het. & het. \\
\hline G & het. & het. & het. & het. & het. \\
\hline
\end{tabular}

hom. = variâncias homogêneas;

het. = variâncias heterogêneas pelo teste de Bartlett a 5\% de probabilidade de erro.

Ciência Rural, v.38, n.9, dez, 2008. 
Tabela 3 - Valores da intensidade amostral total por hectare para a quantidade de serapilheira acumulada em moldura coletora muito pequena $\left(0,25 \mathrm{~m}^{2}\right)$, nas quatro estações sazonais, em quatro limites de erro de estimação (LE), na Floresta Ombrófila Mista de São Francisco de Paula, RS. Santa Maria - RS, 2007.

\begin{tabular}{lcccc}
\hline LE & primavera & verão & outono & invemo \\
\hline $10 \%$ & 52 & 31 & 70 & 58 \\
$15 \%$ & 25 & 15 & 33 & 27 \\
$20 \%$ & 15 & 10 & 20 & 17 \\
$25 \%$ & 11 & 7 & 14 & 12 \\
\hline
\end{tabular}

moldura, reforçando assim que a amostragem deverá ser definida de acordo com a estação sazonal a ser representada. Admitindo-se 15\% de limite de erro de estimação, verifica-se que os valores do tamanho da amostra obtidos para o inverno (27), para a primavera (25), para o outono (33) e para o verão (15) são compatíveis com alguns resultados descritos na literatura (CUNHA et al., 1993; KÖNIG et al., 2002; ARATO et al., 2003), cujos valores estão entre 15 e 33 amostras, respectivamente para o verão e o outono.

\section{CONCLUSÕES}

A quantidade de serapilheira coletada não diferiu no que se refere aos diferentes tamanhos de molduras coletoras em qualquer uma das estações sazonais. Entre as estações sazonais houve variação dos valores da serapilheira coletada, independente do tamanho da moldura usada, e heterogeneidade da variância.

Para um limite de erro de estimação de 15\%, o tamanho da amostra estimado para a moldura de $0,25 \mathrm{~m}^{2}$ de área foi de $25,15,33$ e 27 amostras para as estações sazonais primavera, verão, outono e inverno, respectivamente.

\section{REFERÊNCIAS}

ARATO, H.D. et al. Produção e decomposição de serapilheira em um sistema agroflorestal implantado para recuperação de área degradada em Viçosa-MG. Revista Árvore, v.27, n.5, p.715-721, 2003.

BACKES, A. et al. Produção de folhedo em uma floresta com Araucaria angustifolia no Sul do Brasil. Revista de Pesquisas Botânicas, n.50, p.97-117, 2000.

BACKES, A. et al. Produção de serapilheira em Floresta Ombrófila Mista, em São Francisco de Paula, Rio Grande do Sul, Brasil. Acta Botânica Brasileira, n.19, p.155-160, 2005.

BORÉM, R.A.T.; RAMOS, D.P. Variação estacional e topográfica de nutrientes na serapilheira de um fragmento de Mata Atlântica. Revista Cerne, v.8, n.2, p.42-59, 2002.
CORREIA, M.E.F; ANDRADE, A.G. Formação de serapilheira e ciclagem de nutrientes. In: SANTOS, G.A; CAMARGO, F.A. Fundamentos da matéria orgânica do solo: ecossistemas tropicais e subtropicais. Porto Alegre: Gênesis, 1999. p.209214.

CUNHA, G.C. Aspectos da ciclagem de nutrientes em diferentes fases sucessionais de uma Floresta Estacional do Rio Grande do Sul. 1997. 86f. Dissertação (Mestrado Ciências Florestais) - Escola Superior de Agricultura "Luiz de Queiroz”. Piracicaba.

CUNHA, G.C. et al. Dinâmica nutricional em Floresta Estacional Decidual com ênfase aos minerais provenientes da deposição da serapilheira. Ciência Florestal, v.3, n.1, p.3564, 1993.

FERNANDES, A.V.; BACKES, A. Produtividade primária em floresta com Araucaria angustifolia no Rio Grande do Sul. Iheringia, Série botânica, v.51, n.1, p.63-78, 1998.

GALLON, M.M.P. Um estudo sobre a dinâmica de sistemas complexo a partir de séries temporais de dados microclimáticos para uma floresta de transição no Noroeste do Mato Grosso. 2004. 115f. Dissertação (Mestrado em Engenharia Florestal) - Universidade Federal do Mato Grosso.

GONZALEZ, M.I.M.; GALLARDO, J.F. El efecto hojarasca: una revision. Anales de Edafologia y Agrobiologia, v.41. p.1130-1157, 1982.

IBAMA. Floresta Nacional de São Francisco de Paula FLONA/RS. Brasília, 2000. 6p. (Folder).

KÖNIG, F.G. et al. Avaliação da sazonalidade da produção de serapilheira numa floresta estacional decidual no município de Santa Maria-RS. Revista Árvore, v.26, n.4, p.429-435, 2002.

MIRANDA, J.B.F. Princípios de experimentação e análise estatística. In: PATERNIANI, E. (Ed.) Melhoramento e produção do milho no Brasil. Piracicaba: Fundação Cargill, 1978. 650p.

MOREIRA, P.R.; SILVA, O.A. Produção de serapilheira em área reflorestada. Revista Árvore, v.28, n.1, p.49-59, 2004.

MORENO, J.A. Clima do Rio Grande do Sul. Porto Alegre: Secretaria da Agricultura, 1961. 42p.

PILLAR, V.P. Suficiência amostral. In: BICUDO, C.E.M.; BICUDO D.C. (Ed.). Amostragem em limnologia. São Carlos: Rima, 2004. p.25-43.

PIMENTEL GOMES, F. O problema de tamanho das parcelas em experimentos com plantas arbóreas. Pesquisa Agropecuária Brasileira, v.19, n.12, p.1507-1512, 1984.

POGGIANI, F.; SCHUMACHER, M.V. Ciclagem de nutrientes em florestas nativas. I n: GONÇALVES, J.L.M.; BENEDETTI, V. Nutrição e fertilização florestal. Piracicaba: Instituto de Pesquisas Florestais. 2000. p.287-308.

SANTOS, S.L.; VÁLIO, I.F.M. Litter accumulation and its effect on seedling recruitment in Southeast Brazilian Tropical Forest. Revista Brasileira de Botânica, v.25, n.1, p.89-92, 2002. 
SCHUMACHER, M.V. et al. Produção de serapilheira em uma floresta de Araucaria angustifolia (bertol.) kuntze no município de Pinhal Grande-RS. Revista Árvore, v.28, n.1, p.29-37, 2004.

SEMA/UFSM-RS. Governo do Estado. Relatório final do inventário florestal contínuo do Rio Grande do Sul. Porto Alegre, 2001. V.1 e 2, 706p.

SOUZA, J.A.; DAVIDE, A.C. Deposição de serapilheira e nutrientes em uma mata não minerada e em plantações de bracatinga (Mimosa scabrella) e de eucalipto (Eucalyptus saligna) em áreas de mineração de bauxita. Revista Cerne, v.7, n.1, p.101-113, 2001.
STEEL, R.G.D. et al. Principles and procedures of statistics: a biometrical approach. 3.ed. New York: McGraw Hill Book, 1997. 666p.

STRECK, E.V. et al. Solos do Rio Grande do Sul. Porto Alegre: Emater-RS/UFRGS, 2002. 107p.

VITAL, A.R.T. et al. Produção de serapilheira e ciclagem de nutrientes de uma Floresta Estacional Semidecidual em zona ripária. Revista Árvore, v.28, n.6, p.793-800, 2004. 